\title{
$N$-(acyl)- $N^{\prime}$-(ferrocenylidene)hydrazines and their nickel(II) complexes: Syntheses, structures and physical properties ${ }^{\dagger}$
}

\author{
G NARENDRA BABU and SAMUDRANIL PAL*(D) \\ School of Chemistry, University of Hyderabad, Hyderabad, Telengana 500 046, India \\ E-mail: spal@uohyd.ac.in
}

MS received 21 March 2017; revised 13 April 2017; accepted 14 April 2017

\begin{abstract}
The Schiff bases $N$-(acyl)- $N^{\prime}$-(ferrocenylidene)hydrazines (HFcah (1) and HFcbh (2), where acyl= acetyl in $\mathbf{1}$ and benzoyl in $\mathbf{2}$ and $\mathrm{H}$ represents the dissociable amide proton) were synthesized in high yields (74 and $81 \%$ ) by condensation reactions of equimolar amounts of ferrocene-carboxaldehyde and the corresponding acylhydrazines in presence of acetic acid in refluxing methanol. Reactions of $\mathrm{Ni}(\mathrm{OAc})_{2} \cdot 4 \mathrm{H}_{2} \mathrm{O}$, the Schiff bases $(\mathbf{1}$ and 2) and $\mathrm{NaOAc} \cdot 3 \mathrm{H}_{2} \mathrm{O}$ in 1:2:4 mole ratio in refluxing methanol afforded the diamagnetic iron(II)-nickel(II)iron(II) species $\left[\mathrm{Ni}(\mathrm{Fcah})_{2}\right](3)$ and $\left[\mathrm{Ni}(\mathrm{Fcbh})_{2}\right](4)$ in 60 and $68 \%$ yields, respectively. Both Schiff bases and the two trinuclear complexes were characterized by elemental (CHN) analysis, mass spectrometric, various spectroscopic (IR, UV-Vis and ${ }^{1} \mathrm{H}$ NMR) and cyclic voltammetric measurements. Molecular structures of 2, 3 and $\mathbf{4}$ were determined by single crystal X-ray diffraction studies. The cyclopentadienide rings in the ferrocene moieties are essentially in eclipsed conformation in all three structures. Deprotonated Schiff base ligands in each complex ( $\mathrm{Fcah}^{-}$in $\mathbf{3}$ and $\mathrm{Fcbh}^{-}$in $\mathbf{4}$ ) act as five-membered chelate ring forming azomethine-N and amidate-O donors and assemble a square-planar trans $-\mathrm{N}_{2} \mathrm{O}_{2}$ coordination environment around the nickel centre. The redox active 1-4 exhibit an iron centred redox couple in the potential range $0.23-0.50 \mathrm{~V}$ (vs. $\mathrm{Ag} / \mathrm{AgCl}$ ).
\end{abstract}

Keywords. Nickel (II); ferrocene; acylhydrazones; crystal structures; physical properties.

\section{Introduction}

Since the discovery of ferrocene and elucidation of its structure, ${ }^{1-4}$ it has attracted enormous attention due to its exceptional stability, electron-transfer properties and benzene-like versatile reactivity. These properties have led to the development of a vast number of ferrocene derivatives and their applications in a wide range of research areas such as catalytic organic synthesis, biological and medicinal chemistry, agrochemicals and materials science. ${ }^{5-15}$ Consequently, there is a continuous endeavour to design and synthesize ferrocene containing new molecules, which will have potential utility as functional materials or catalysts in organic synthetic reactions. Recently, we have reported a dipalladium(II) complex with a ferrocene containing diphosphine ligand ${ }^{16}$ and its application as catalyst in C-C cross coupling reactions. ${ }^{17} \mathrm{In}$

\footnotetext{
*For correspondence

$\dagger$ Dedicated to Professor K. C. Kumara Swamy on the occasion of his 60th birth anniversary.
}

the present work, we have explored the coordination chemistry of the Schiff bases $N$-(acetyl/benzoyl)- $N^{\prime}$ (ferrocenylidene)hydrazines with nickel(II). The reason for choosing these Schiff bases, other than having the redox active ferrocene moiety, is the presence of high oxidation state promoting $\mathrm{O}$-coordinating amide functionality which can provide transition metal ion complexes with interesting electron transfer behaviour, a prerequisite for molecular materials and redox catalysts. Herein, we report the syntheses, structures and physical properties of the Schiff bases HFcah (1) and HFcbh (2) and their corresponding nickel(II) complexes $\left[\mathrm{Ni}(\mathrm{Fcah})_{2}\right](3)$ and $\left[\mathrm{Ni}(\mathrm{Fcbh})_{2}\right](4)$ containing the angular trinuclear iron(II)-nickel(II)-iron(II) array (Scheme 1).

\section{Experimental}

\subsection{Materials}

All the chemicals used in this work were of analytical grade available commercially and were used as supplied without any

Electronic supplementary material: The online version of this article (doi:10.1007/s12039-017-1280-8) contains supplementary material, which is available to authorized users. 


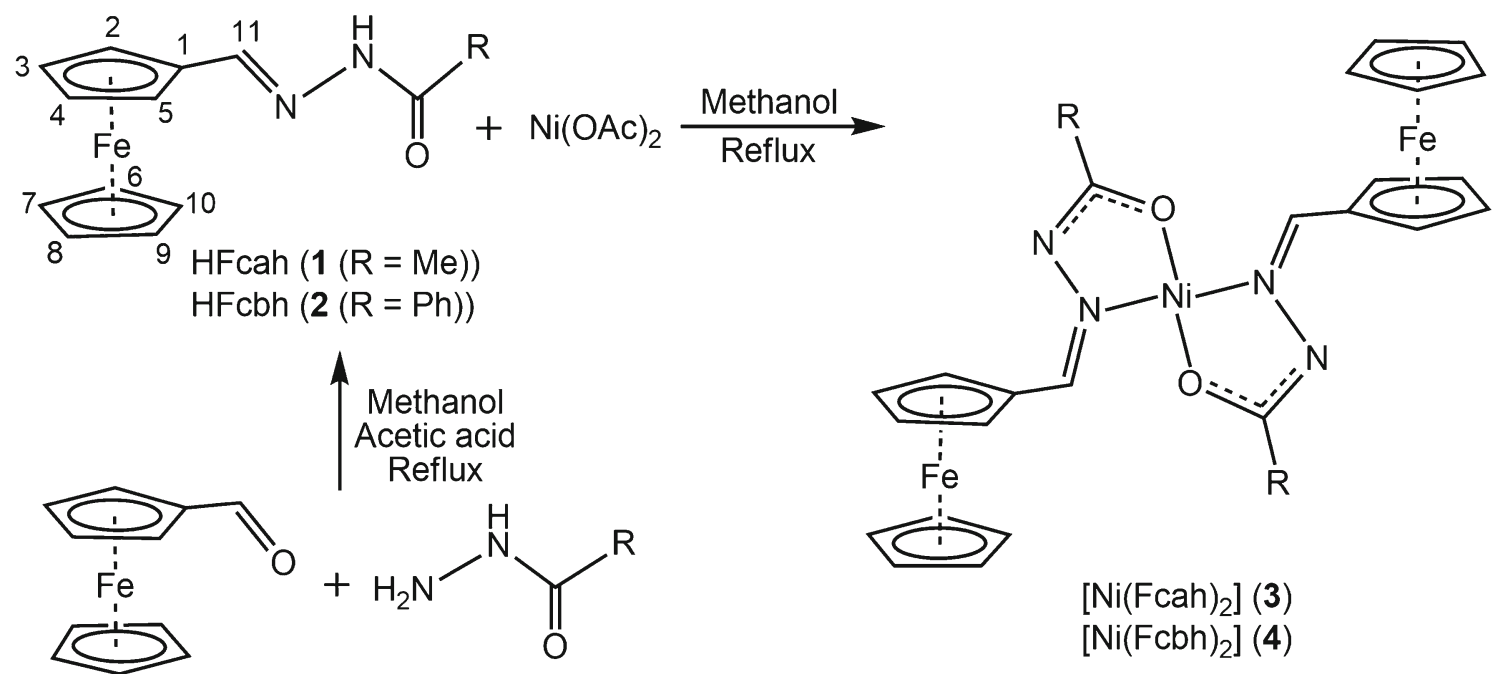

Scheme 1. Syntheses of $N$-(acyl)- $N^{\prime}$-(ferrocenylidene)hydrazines and their Ni(II) complexes

further purification. Solvents used were purified by standard methods. ${ }^{18}$

\subsection{Physical measurements}

Elemental ( $\mathrm{CHN})$ analysis data were obtained with the help of a Thermo Finnigan Flash EA1112 series elemental analyser. Purity of the Schiff bases was checked using a Shimadzu LCMS 2010 liquid chromatograph mass spectrometer. A Bruker Maxis ESI-TOF spectrometer was used to record the high-resolution mass spectra. Magnetic susceptibility measurements were performed using a Sherwood Scientific balance. A Digisun DI-909 conductivity meter was used to measure the solution electrical conductivities. Infrared spectra were recorded on a Thermo Scientific Nicolet 380 FT-IR spectrophotometer. A Shimadzu UV-3600 UV-VisNIR spectrophotometer was used to collect the electronic spectra. The ${ }^{1} \mathrm{H}$ NMR spectra were acquired on a Bruker $400 \mathrm{MHz}$ spectrometer. A CH-Instruments model 620A electrochemical analyser was employed for cyclic voltammetric measurements.

\subsection{Synthesis of HFcah $(\mathbf{1})$}

A mixture of acetylhydrazine $(0.37 \mathrm{~g}, 5 \mathrm{mmol})$ and ferrocenecarboxaldehyde $(1.07 \mathrm{~g}, 5 \mathrm{mmol})$ was taken in methanol $(30 \mathrm{~mL})$ and a few drops of acetic acid were added. The resulting mixture was refluxed for $12 \mathrm{~h}$. The dark brown solid separated was filtered off and recrystallized from chloroform. Yield: $1.01 \mathrm{~g}(74 \%)$. Anal. Calcd. for $\mathrm{C}_{13} \mathrm{H}_{14} \mathrm{FeN}_{2} \mathrm{O}$ : C, 57.81; H, 5.22; N, 10.37\%. Found: C, 57.72; H, 5.26; N, 10.26\%. LCMS $\mathrm{m} / \mathrm{z}$ for $\{\mathrm{M}+\mathrm{H}\}^{+}$found (calcd.): 271.15 (270.97). Selected IR bands: $v\left(\mathrm{~cm}^{-1}\right)=3187$ (amide$\mathrm{NH}), 1671$ (amide-CO), 1605 (azomethine-CN). UV-Vis in $\mathrm{CH}_{2} \mathrm{Cl}_{2}: \lambda_{\max }(\mathrm{nm})\left(\varepsilon\left(10^{4} \mathrm{M}^{-1} \mathrm{~cm}^{-1}\right)\right)=460(0.05), 340^{\text {sh }}$ (0.12), 292 (1.42), 250 (1.33). ${ }^{1} \mathrm{H}$ NMR in $\mathrm{CDCl}_{3}: \delta(\mathrm{ppm})=$ $9.52(\mathrm{~s}, 1 \mathrm{H}, \mathrm{NH}), 7.68\left(\mathrm{~s}, 1 \mathrm{H}, \mathrm{H}^{11}\right), 4.61\left(\mathrm{~s}, 2 \mathrm{H}, \mathrm{H}^{2}, \mathrm{H}^{5}\right), 4.40$ (s, 2H, H $\left.\mathrm{H}^{3}, \mathrm{H}^{4}\right), 4.22\left(\mathrm{~s}, 5 \mathrm{H}, \mathrm{H}^{6-10}\right), 2.34$ (s, 3H, R $\left.=\mathrm{CH}_{3}\right)$. $\mathrm{CV}$ data in $\mathrm{CH}_{2} \mathrm{Cl}_{2}: \mathrm{E}_{1 / 2}(\mathrm{~V})\left(\Delta \mathrm{E}_{p}(\mathrm{mV})\right)=0.23(160)$.

\subsection{Synthesis of HFcbh (2)}

To a methanol solution $(30 \mathrm{~mL})$ of benzoylhydrazine $(0.68 \mathrm{~g}$, $5 \mathrm{mmol}$ ) and ferrocene-carboxaldehyde (1.07 $\mathrm{g}, 5 \mathrm{mmol})$ few drops of acetic acid were added and the mixture was boiled under reflux for $9 \mathrm{~h}$. The brown solid formed was collected by filtration and recrystallized from chloroform. Yield: $1.34 \mathrm{gm}(81 \%)$. Anal. Calcd. for $\mathrm{C}_{18} \mathrm{H}_{16} \mathrm{FeN}_{2} \mathrm{O}: \mathrm{C}, 65.08 ; \mathrm{H}$, 4.85; N, 8.43\%. Found: C, 65.17; H, 4.91; N, 8.36\%. LCMS $\mathrm{m} / \mathrm{z}$ for $\{\mathrm{M}+\mathrm{H}\}^{+}$found (calcd.): 333.15 (332.98). Selected IR bands: $v\left(\mathrm{~cm}^{-1}\right)=3191$ (amide-NH), 1638 (amide$\mathrm{CO}), 1605$ (azomethine-CN). UV-Vis in $\mathrm{CH}_{2} \mathrm{Cl}_{2}: \lambda_{\max }(\mathrm{nm})$ $\left(\varepsilon\left(10^{4} \mathrm{M}^{-1} \mathrm{~cm}^{-1}\right)\right)=456(0.09), 360^{\text {sh }}(0.23), 300(1.43)$, 258 (1.12). ${ }^{1} \mathrm{H}$ NMR in $\mathrm{CDCl}_{3}: \delta(\mathrm{ppm})=9.05(\mathrm{~s}, 1 \mathrm{H}, \mathrm{NH})$, $8.27\left(\mathrm{~s}, 1 \mathrm{H}, \mathrm{H}^{11}\right), 7.87(\mathrm{~s}, 2 \mathrm{H}$, ortho $\mathrm{Hs}$ of $\mathrm{R}=\mathrm{Ph}), 7.57-7.49$ $(\mathrm{m}, 3 \mathrm{H}$, meta and para $\mathrm{Hs}$ of $\mathrm{R}=\mathrm{Ph}), 4.74\left(\mathrm{~s}, 2 \mathrm{H}, \mathrm{H}^{2}, \mathrm{H}^{5}\right)$, $4.45\left(\mathrm{~s}, 2 \mathrm{H}, \mathrm{H}^{3}, \mathrm{H}^{4}\right), 4.24\left(\mathrm{~s}, 5 \mathrm{H}, \mathrm{H}^{6-10}\right)$. $\mathrm{CV}$ data in $\mathrm{CH}_{2} \mathrm{Cl}_{2}$ : $\mathrm{E}_{1 / 2}(\mathrm{~V})\left(\Delta \mathrm{E}_{p}(\mathrm{mV})\right)=0.36(130)$.

\subsection{Synthesis of $\left[\mathrm{Ni}(\mathrm{Fcah})_{2}\right](\mathbf{3})$}

A mixture of $\mathrm{Ni}(\mathrm{OAc})_{2} \cdot 4 \mathrm{H}_{2} \mathrm{O}(0.25 \mathrm{~g}, 1 \mathrm{mmol})$, HFcah ( $0.54 \mathrm{gm}, 2 \mathrm{mmol})$ and $\mathrm{NaOAc} \cdot 3 \mathrm{H}_{2} \mathrm{O}(0.55 \mathrm{~g}, 4 \mathrm{mmol})$ was taken in $30 \mathrm{~mL}$ of methanol and heated to boiling under reflux for $8 \mathrm{~h}$. The brown solid precipitated was filtered off, washed first with water $(20 \mathrm{~mL})$ and then with methanol $(2 \times 10 \mathrm{~mL}$ portions $)$ and finally dried in vacuum. Yield: $0.36 \mathrm{~g} \mathrm{(60 \% ).} \mathrm{Anal.} \mathrm{Calcd.} \mathrm{for} \mathrm{C}_{26} \mathrm{H}_{26} \mathrm{~N}_{4} \mathrm{O}_{2} \mathrm{Fe}_{2} \mathrm{Ni}$ : C, 52.32; $\mathrm{H}, 4.39$; N, 9.39\%. Found: C, 52.41; H, 4.32; N, 9.45\%. HRMS $\mathrm{m} / \mathrm{z}$ for $\{\mathrm{M}+\mathrm{H}\}^{+}$found (calcd.): 597.02 (597.60). Selected IR bands: $v\left(\mathrm{~cm}^{-1}\right)=1614$ (amidate-CO), 1552 (amidate-CN-NC-azomethine). UV-Vis in $\mathrm{CH}_{2} \mathrm{Cl}_{2}: \lambda_{\max }$ (nm) $\left(\varepsilon\left(10^{4} \mathrm{M}^{-1} \mathrm{~cm}^{-1}\right)\right)=475(0.32), 377(1.41), 330^{\mathrm{sh}}$ (1.28), 295 (1.56), 263 (1.57). ${ }^{1} \mathrm{H}$ NMR in $\mathrm{CDCl}_{3}: \delta$ (ppm) = $6.83\left(\mathrm{~s}, 1 \mathrm{H}, \mathrm{H}^{11}\right), 5.03\left(\mathrm{~s}, 2 \mathrm{H}, \mathrm{H}^{2}, \mathrm{H}^{5}\right), 4.49\left(\mathrm{~s}, 2 \mathrm{H}, \mathrm{H}^{3}, \mathrm{H}^{4}\right)$, 
$4.31\left(\mathrm{~s}, 5 \mathrm{H}, \mathrm{H}^{6-10}\right), 1.95\left(\mathrm{~s}, 3 \mathrm{H}, \mathrm{R}=\mathrm{CH}_{3}\right) . \mathrm{CV}$ data in $\mathrm{CH}_{2} \mathrm{Cl}_{2}: \mathrm{E}_{1 / 2}(\mathrm{~V})\left(\Delta \mathrm{E}_{p}(\mathrm{mV})\right)=0.50(210)$.

\subsection{Synthesis of $\left[\mathrm{Ni}(\mathrm{Fcbh})_{2}\right](\mathbf{4})$}

To $30 \mathrm{~mL}$ of methanol, $\mathrm{Ni}(\mathrm{OAc})_{2} \cdot 4 \mathrm{H}_{2} \mathrm{O}(0.25 \mathrm{~g}, 1 \mathrm{mmol})$, $\mathrm{HFcbh}(0.67 \mathrm{gm}, 2 \mathrm{mmol})$ and $\mathrm{NaOAc} \cdot 3 \mathrm{H}_{2} \mathrm{O}(0.55 \mathrm{~g}, 4 \mathrm{mmol})$ were added and the mixture was boiled under reflux for $8 \mathrm{~h}$. The brick-red solid formed was collected by filtration, washed with water $(20 \mathrm{~mL})$ followed by $2 \times 10 \mathrm{~mL}$ portions of methanol and finally dried in vacuum. Yield: $(0.49 \mathrm{~g}, 68 \%)$. Anal. Calcd. for $\mathrm{C}_{36} \mathrm{H}_{30} \mathrm{~N}_{4} \mathrm{O}_{2} \mathrm{Fe}_{2} \mathrm{Ni}$ : C, 59.97; $\mathrm{H}, 4.19$; N, 7.77\%. Found: C, 59.85; H, 4.25; N, 7.71\%. HRMS $\mathrm{m} / \mathrm{z}$ for $\{\mathrm{M}+\mathrm{H}\}^{+}$found (calcd.): 721.05 (721.63). Selected IR bands: $\nu\left(\mathrm{cm}^{-1}\right)=1614$ (amidate-CO), 1585 (amidate-CN-NC-azomethine). UV-Vis in $\mathrm{CH}_{2} \mathrm{Cl}_{2}: \lambda_{\max }$ (nm) $\left(\varepsilon\left(10^{4} \mathrm{M}^{-1} \mathrm{~cm}^{-1}\right)\right)=488(0.64), 390(1.97), 335^{\mathrm{sh}}$ (2.23), 305 (2.98), $265^{\text {sh }}$ (2.62). ${ }^{1} \mathrm{H} \mathrm{NMR}$ in $\mathrm{CDCl}_{3}: \delta$ (ppm) $\left(\mathrm{J}_{\mathrm{H}-\mathrm{H}}(\mathrm{Hz})\right)=8.03(8)(\mathrm{d}, 2 \mathrm{H}$, ortho $\mathrm{Hs}$ of $\mathrm{R}=\mathrm{Ph}), 7.51-$ $7.42(\mathrm{~m}, 3 \mathrm{H}$, meta and para $\mathrm{Hs}$ of $\mathrm{R}=\mathrm{Ph}), 7.18(\mathrm{~s}, 1 \mathrm{H}$, $\left.\mathrm{H}^{11}\right), 5.19\left(\mathrm{~s}, 2 \mathrm{H}, \mathrm{H}^{2}, \mathrm{H}^{5}\right), 4.60\left(\mathrm{~s}, 2 \mathrm{H}, \mathrm{H}^{3}, \mathrm{H}^{4}\right), 4.34(\mathrm{~s}$, $\left.5 \mathrm{H}, \mathrm{H}^{6-10}\right) . \mathrm{CV}$ data in $\mathrm{CH}_{2} \mathrm{Cl}_{2}: \mathrm{E}_{1 / 2}(\mathrm{~V})\left(\Delta \mathrm{E}_{p}(\mathrm{mV})\right)$ $=0.47(210)$.

\section{$2.7 \quad X$-ray crystallography}

X-ray quality crystals of the Schiff base HFcbh (2) were obtained as $\mathbf{2} \cdot \mathrm{CDCl}_{3}$ from its $\mathrm{CDCl}_{3}$ solution in a NMR tube. On the other hand, single crystals of the complexes $\left[\mathrm{Ni}(\mathrm{Fcah})_{2}\right](3)$ and $\left[\mathrm{Ni}(\mathrm{Fcbh})_{2}\right](\mathbf{4})$ were grown by slow evaporation of their solutions in chloroform-acetonitrile (1:1) mixture. Complex $\mathbf{3}$ crystallized as it is without any solvent molecule, while complex $\mathbf{4}$ formed a chloroform solvate 4. $\mathrm{CHCl}_{3}$. X-ray intensity data for $\mathbf{2} \cdot \mathrm{CDCl}_{3}$ were collected at $298 \mathrm{~K}$ on a Bruker-Nonius SMART APEX CCD single crystal diffractometer using graphite-monochromated Mo $K \alpha$ radiation $(\lambda=0.71073 \AA)$. The SMART and the SAINTPlus packages ${ }^{19}$ were used for data collection and reduction, respectively. A Bruker D8 QUEST diffractometer equipped with a PHOTON 100 CMOS area detector and an INCOATEC microfocus source for graphite-monochromated Mo $K \alpha$ radiation $(\lambda=0.71073 \AA)$ was used to acquire X-ray intensity data from 3 and $4 \cdot \mathrm{CHCl}_{3}$-at $298 \mathrm{~K}$. Data collection and reduction were performed using APEX2 and SAINT-Plus packages, respectively. ${ }^{20}$ Absorption corrections were done with the help of SADABS program. ${ }^{21}$ The structures of 2. $\mathrm{CDCl}_{3}, 3$ and $4 \cdot \mathrm{CHCl}_{3}$ were solved by direct method in the space groups $P 3_{1}, P 2_{1} / \mathrm{c}$ and $P 2_{1} / \mathrm{n}$, respectively. The asymmetric unit of each of $\mathbf{2} \cdot \mathrm{CDCl}_{3}$ and $\mathbf{4} \cdot \mathrm{CHCl}_{3}$ contains one complex molecule and a solvent molecule, while that of $\mathbf{3}$ contains one molecule of the complex. Each structure was refined on $F^{2}$ by full-matrix least-squares procedures. All non-hydrogen atoms were refined with anisotropic displacement parameters. The hydrogen atoms were included in the structure factor calculations at idealized positions by using a riding model. The SHELX-97 programs ${ }^{22}$ accessed via the WinGX package ${ }^{23}$ were used for structure solution and refinement. The structural illustrations were prepared using ORTEP-3 for Windows. ${ }^{24}$ Selected crystal data and refinement summary for all three structures are listed in Table 1.

\section{Results and Discussion}

\subsection{Synthesis and characterization}

The Schiff bases HFcah (1) and HFcbh (2) were synthesised in very good yields ( 74 and $81 \%$ ) by condensation reactions of equimolar amounts of ferrocenecarboxaldehyde and the corresponding acylhydrazines (acetylhydrazine and benzoylhydrazine) in methanol in presence of a few drops of acetic acid (Scheme 1). Both $\mathbf{1}$ and $\mathbf{2}$ were characterized by elemental analysis, mass spectrometric and spectroscopic (IR and ${ }^{1} \mathrm{H}$ NMR) measurements. The characterisation data are consistent with their molecular formulas and structures. The nickel(II) complexes $\left[\mathrm{Ni}(\mathrm{Fcah})_{2}\right](3)$ and $\left[\mathrm{Ni}(\mathrm{Fcbh})_{2}\right]$ (4) were synthesized in 60 and $68 \%$ yields, respectively, by reacting $\mathrm{Ni}(\mathrm{OAc})_{2} \cdot 4 \mathrm{H}_{2} \mathrm{O}$, the corresponding Schiff bases and NaOAc $\cdot 3 \mathrm{H}_{2} \mathrm{O}$ in 1:2:4 mole ratio in boiling methanol. The elemental analysis data of $\mathbf{3}$ and $\mathbf{4}$ are in good agreement with their molecular formulas. They are highly soluble in dichloromethane, chloroform, dimethylsulfoxide and dimethylformamide; sparingly soluble in acetonitrile and methanol and insoluble in $n$-hexane and toluene. Room temperature magnetic susceptibility measurements with powdered samples of $\mathbf{3}$ and $\mathbf{4}$ revealed their diamagnetic nature. Thus, the nickel centres in each complex are in +2 oxidation state and have square-planar coordination environments. In solution, the electrically non-conducting behaviour of both complexes supports their molecular formulas as neutral species.

\subsection{X-ray molecular structures}

Molecular structures of $\mathbf{2 , 3}$ and $\mathbf{4}$ determined by single crystal X-ray diffraction analyses are depicted in Figures 1, 2 and 3, respectively. Selected geometric parameters are listed in Table 2. In all three structures, the planar cyclopentadienide $\left(\mathrm{Cp}^{-}\right)$rings in the $\mathrm{FeCp}_{2}$ fragments are essentially parallel. The dihedral angles between the two $\mathrm{Cp}^{-}$planes span the range $0.16(23)-2.75(21)^{\circ}$. The double-decker $\mathrm{FeCp}_{2}$ units are in the eclipsed rather than the staggered conformation. The torsion angles involving the opposing corners of the $\mathrm{Cp}^{-}$rings are in the ranges $2.80-4.91^{\circ}$ for $2,4.40-6.45^{\circ}$ and $2.53-3.47^{\circ}$ for 3 and $3.65-4.89^{\circ}$ 
Table 1. Selected crystal data and structure refinement summary.

\begin{tabular}{llll}
\hline Compound & $\mathbf{2} \cdot \mathrm{CDCl}_{3}$ & $\mathbf{3}$ & $\mathbf{4} \cdot \mathrm{CHCl}_{3}$ \\
\hline Chemical formula & $\mathrm{C}_{19} \mathrm{H}_{16} \mathrm{DN}_{2} \mathrm{OCl}_{3} \mathrm{Fe}$ & $\mathrm{C}_{26} \mathrm{H}_{26} \mathrm{~N}_{4} \mathrm{O}_{2} \mathrm{Fe}_{2} \mathrm{Ni}$ & $\mathrm{C}_{37} \mathrm{H}_{31} \mathrm{~N}_{4} \mathrm{O}_{2} \mathrm{Cl}_{3} \mathrm{Fe}_{2} \mathrm{Ni}$ \\
Formula weight & 452.55 & 596.92 & 840.42 \\
Crystal system & Trigonal & Monoclinic & Monoclinic \\
Space group & $P 3_{1}$ & $P 21 / \mathrm{c}$ & $P 2{ }_{1} / \mathrm{n}$ \\
$a(\AA)$ & $12.3802(12)$ & $11.6562(5)$ & $16.5132(13)$ \\
$b(\AA)$ & $12.3802(12)$ & $20.5748(9)$ & $13.1438(11)$ \\
$c(\AA)$ & $11.623(2)$ & $11.5414(4)$ & $16.8401(15)$ \\
$\alpha\left({ }^{\circ}\right)$ & 90 & 90 & 90 \\
$\beta\left(^{\circ}\right)$ & 90 & $119.312(1)$ & $107.255(3)$ \\
$\gamma\left({ }^{\circ}\right)$ & 120 & 90 & 90 \\
Volume $\left(\AA^{3}\right)$ & $1542.7(4)$ & $2413.52(17)$ & $3490.6(5)$ \\
$\mathrm{Z}$ & 3 & 4 & 4 \\
$\left.\rho(\mathrm{g} \mathrm{cm})^{-3}\right)$ & 1.461 & 1.643 & 1.599 \\
$\left.\mu(\mathrm{mm})^{-1}\right)$ & 1.133 & 1.990 & 1.624 \\
Reflections collected & 14898 & 28639 & 63579 \\
Reflections unique & 3613 & 4246 & 6124 \\
Reflections $[I \geq 2 \sigma(I)]$ & 2939 & 3658 & 4724 \\
Data/restr./param. & $3613 / 1 / 235$ & $4246 / 0 / 318$ & $6124 / 0 / 442$ \\
$R 1, w R 2[I \geq 2 \sigma(I)]$ & $0.0565,0.1415$ & $0.0273,0.0674$ & $0.0648,0.1750$ \\
$R 1, w R 2[$ all data] & $0.0703,0.1527$ & $0.0350,0.0706$ & $0.0868,0.1887$ \\
GoF on $F^{2}$ & 1.027 & 1.069 & 1.045 \\
Max./Min. $\Delta \rho\left(\mathrm{e} \AA^{-3}\right)$ & $0.482 /-0.274$ & $0.797 /-0.339$ & $1.869 /-1.081$ \\
\hline
\end{tabular}

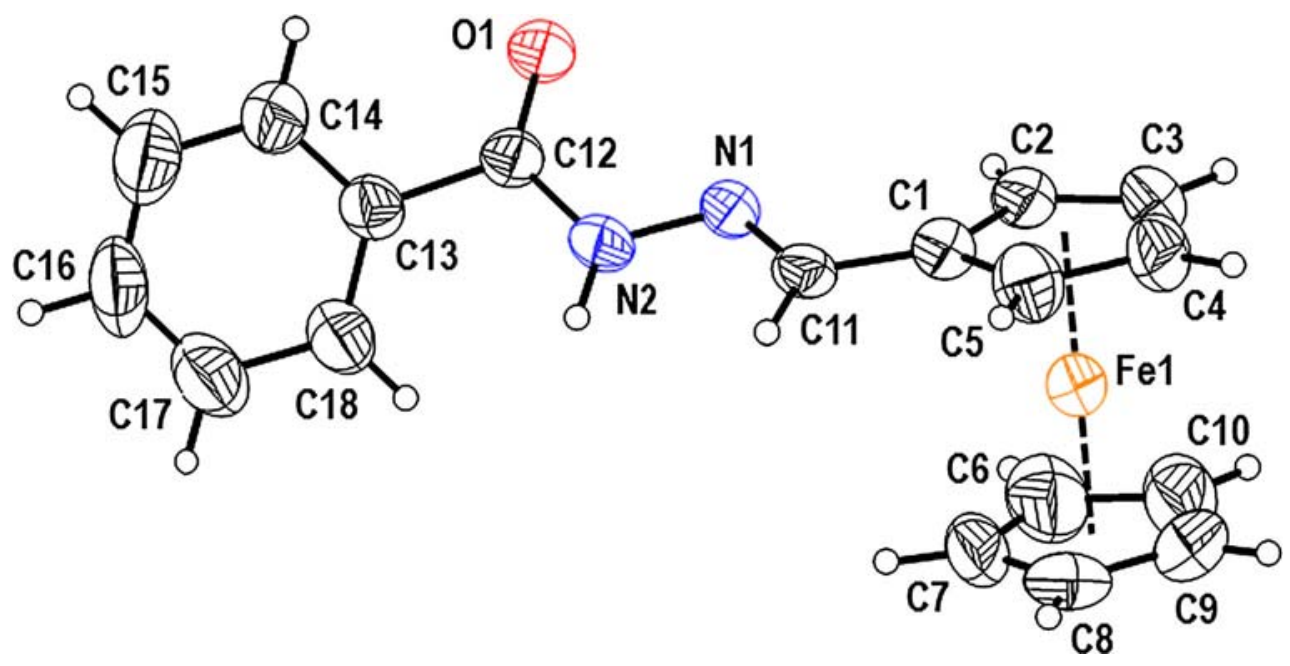

Figure 1. Molecular structure of HFcbh (2) with the atom labeling scheme. Thermal ellipsoids of all non-hydrogen atoms are drawn at the $40 \%$ probability level.

and $10.67-12.03^{\circ}$ for 4 . The $\mathrm{Fe}-\mathrm{Cg}(\mathrm{Cg}=$ centroid of $\left.\mathrm{Cp}^{-}\right)(1.633-1.659 \AA)$ and the $\mathrm{Fe}-\mathrm{C}\left(\mathrm{Cp}^{-}\right)$distances (2.004(8)-2.060(7) $\AA$ ) are comparable with the corresponding distances reported for the eclipsed conformation of $\mathrm{FeCp}_{2} \cdot{ }^{25,26}$ The $\mathrm{C}=\mathrm{O}$ and the $\mathrm{C}-\mathrm{N}$ bond lengths of the amide functionality in $\mathbf{2}$ are shorter (by $0.097 \AA$ ) and longer (by $0.047 \AA$ ), respectively, when compared with the averages of the corresponding bond lengths in $\mathbf{3}$ and $\mathbf{4}$ (Table 2). These differences clearly indicate that the amide functionalities of the ligands in each complex are deprotonated. ${ }^{16,27,29,29}$ Further, the $\mathrm{C}-$ $\mathrm{O}$ and the $\mathrm{C}-\mathrm{N}$ distances in the amidate moieties of the ligands in $\mathbf{3}$ and $\mathbf{4}$ clearly indicate the delocalisation of the corresponding negative charge over the $-(\mathrm{O}) \mathrm{CN}-$ fragment. The ligands ( $\mathrm{Fcah}^{-}$in $\mathbf{3}$ and $\mathrm{Fcbh}^{-}$in $\mathbf{4}$ ) coordinate the nickel centre via the azomethine- $\mathrm{N}$ and the amidate-O atoms to form two five-membered chelate rings and a trans $-\mathrm{N}_{2} \mathrm{O}_{2}$ coordination environment in both complexes (Figures 2 and 3 ). The chelate bite angles $\left(83.4-83.7^{\circ}\right)$ in $\mathbf{3}$ and $\mathbf{4}$ are unexceptional and 


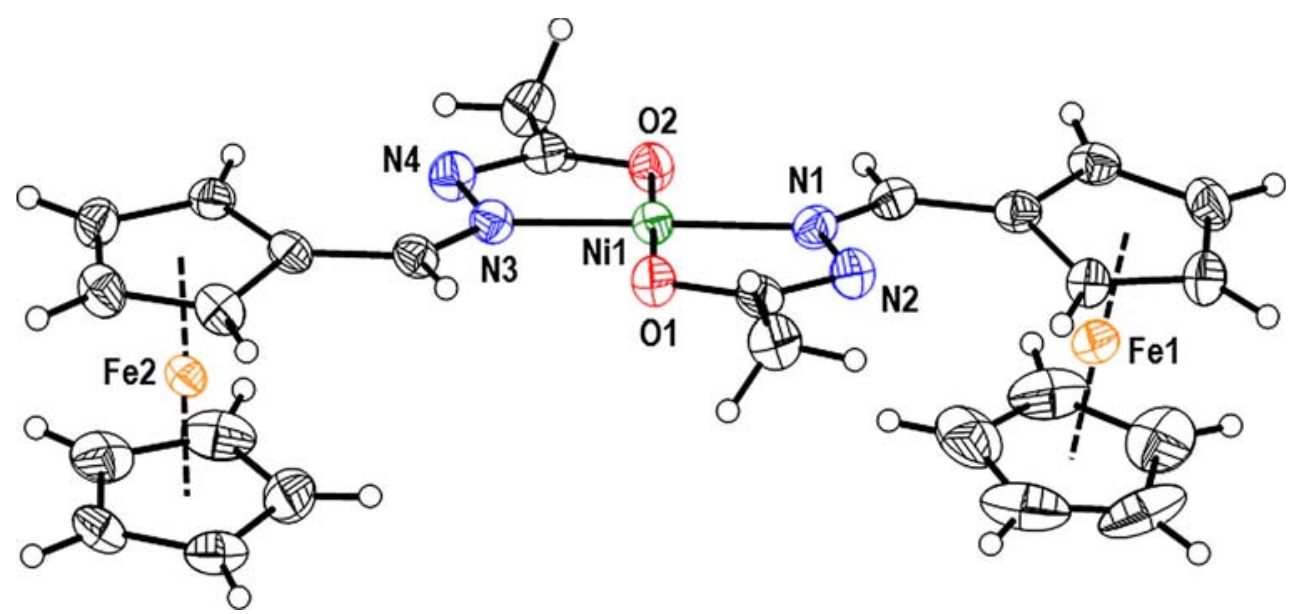

Figure 2. Molecular structure of $\left[\mathrm{Ni}(\mathrm{Fcah})_{2}\right](3)$. Thermal ellipsoids of all non-hydrogen atoms are shown at the $40 \%$ probability level. For clarity only the non-carbon atoms are labeled.

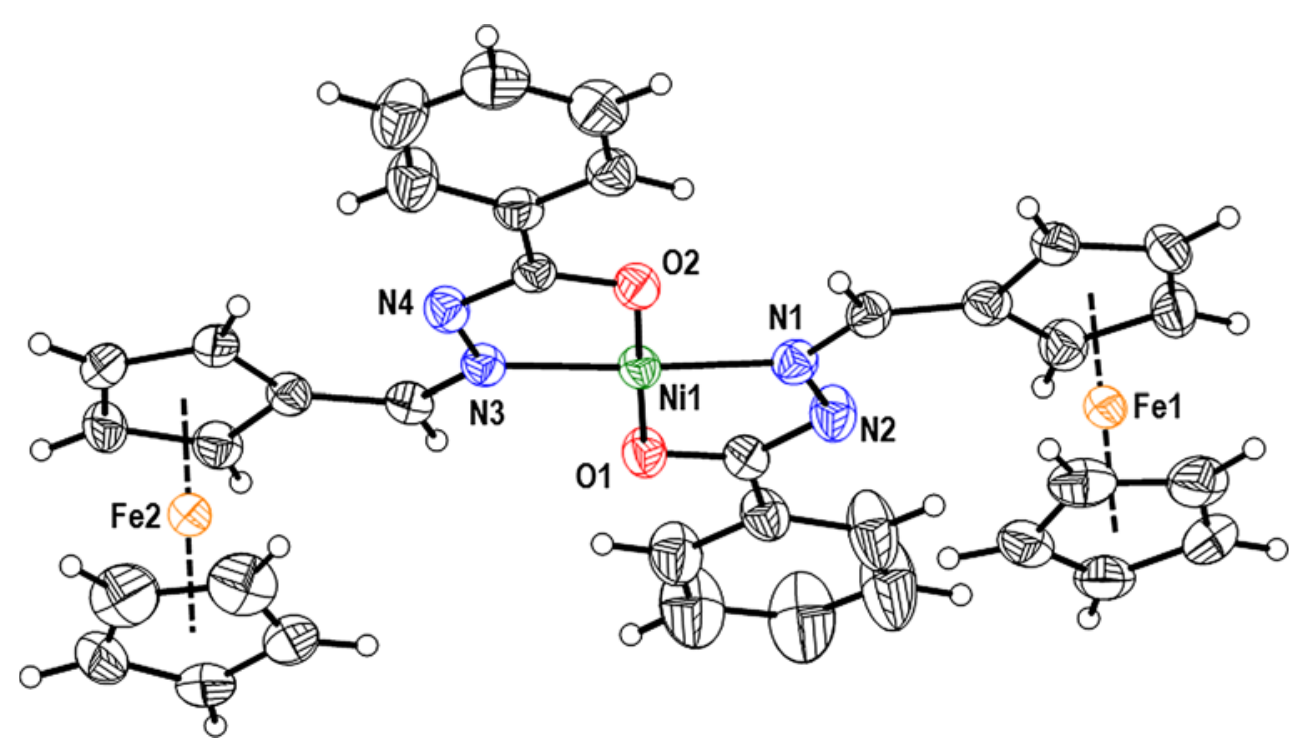

Figure 3. Molecular structure of $\left[\mathrm{Ni}(\mathrm{Fcbh})_{2}\right](4)$. All non-hydrogen atoms are represented by their $40 \%$ probability thermal ellipsoids. For clarity the carbon atoms are not labeled.

very similar to those reported earlier for similar chelate ring containing nickel(II) complexes. ${ }^{28,29}$ The other two cis angles are within $95.8-97.2^{\circ}$. The trans bond angles $\left(177-179^{\circ}\right)$ are very close to the ideal value of $180^{\circ}$. There is no deviation of the metal centre from the plane containing the four coordinating atoms. The root-meansquare deviation from the mean plane constituted by $\mathrm{NiN}_{2} \mathrm{O}_{2}$ is $0.006 \AA$ in 3 and $0.031 \AA$ in 4 . The Ni-N and the Ni-O bond lengths are within the ranges observed for square-planar nickel(II) complexes having similar coordinating atoms. ${ }^{28-30,33}$ Because of the trans $-\mathrm{N}_{2} \mathrm{O}_{2}$ geometry the iron atoms and the unsubstituted $\mathrm{Cp}^{-}$rings of the two $\mathrm{FeCp}_{2}$ units are on the same side of $\mathrm{NiN}_{2} \mathrm{O}_{2}$ plane and, as a result, the shape of the iron(II)-nickel(II)iron(II) array is angular in each of $\mathbf{3}$ and $\mathbf{4}$ (Figures 2 and 3). The average $\mathrm{Ni} \cdots \mathrm{Fe}$ distance in $\mathbf{3}(5.570 \AA)$ is slightly shorter than that $(5.673 \AA)$ in 4 . The $\mathrm{Fe} \cdots \mathrm{Fe}$ distance and the $\mathrm{Fe} \cdots \mathrm{Ni} \cdots \mathrm{Fe}$ angle are $10.525 \AA$ and $141.73^{\circ}$ in 3 and $11.031 \AA$ and $152.95^{\circ}$ in 4 .

\subsection{Spectroscopic properties}

Infrared spectra of 1-4 were recorded by using $\mathrm{KBr}$ pellets in the range $4000-400 \mathrm{~cm}^{-1}$. A large number of bands have been observed in each spectrum. We have not attempted to assign all the bands except for very few. The free Schiff bases $\mathbf{1}$ and $\mathbf{2}$ show the amide-NH stretches at 3187 and $3191 \mathrm{~cm}^{-1}$, respectively. 1 displays a very strong and somewhat broad band at $1671 \mathrm{~cm}^{-1}$ with a shoulder at $1605 \mathrm{~cm}^{-1}$. These two absorptions have 
Table 2. Selected bond parameters $\left(\AA\right.$ and $\left.{ }^{\circ}\right)$ for $\mathbf{2} \cdot \mathrm{CDCl}_{3}, \mathbf{3}$ and $\mathbf{4} \cdot \mathrm{CHCl}_{3}$.

\begin{tabular}{llll}
\hline Compound & $\mathbf{2} \cdot \mathrm{CDCl}_{3}$ & $\mathbf{3}$ & $\mathbf{4} \cdot \mathrm{CHCl}_{3}$ \\
\hline $\mathrm{Fe}-\mathrm{Cg}\left(\mathrm{Cp}^{-}\right)$ & $1.633,1.644$ & $1.645-1.658$ & $1.643-1.659$ \\
$\mathrm{Fe}-\mathrm{C}\left(\mathrm{Cp}^{-}\right)$ & $2.004(8)-2.050(7)$ & $2.029(2)-2.056(3)$ & $2.029(6)-2.060(7)$ \\
$\mathrm{C}-\mathrm{O}($ amide) & $1.204(5)$ & $1.296(3), 1.301(3)$ & $1.298(7), 1.308(6)$ \\
$\mathrm{C}-\mathrm{N}($ amide) & $1.349(6)$ & $1.300(3), 1.304(3)$ & $1.305(7), 1.297(7)$ \\
$\mathrm{C}-\mathrm{N}($ azomethine) & $1.265(6)$ & $1.286(3), 1.290(3)$ & $1.306(7), 1.299(7)$ \\
$\mathrm{Ni}(1)-\mathrm{O}(1)$ & - & $1.8432(16)$ & $1.846(4)$ \\
$\mathrm{Ni}(1)-\mathrm{O}(2)$ & - & $1.8436(16)$ & $1.831(4)$ \\
$\mathrm{Ni}(1)-\mathrm{N}(1)$ & - & $1.866(2)$ & $1.867(5)$ \\
$\mathrm{Ni}(1)-\mathrm{N}(3)$ & - & $1.857(2)$ & $1.868(4)$ \\
$\mathrm{O}(1)-\mathrm{Ni}(1)-\mathrm{O}(2)$ & - & $178.97(8)$ & $178.41(18)$ \\
$\mathrm{O}(1)-\mathrm{Ni}(1)-\mathrm{N}(1)$ & - & $83.52(8)$ & $83.43(18)$ \\
$\mathrm{O}(1)-\mathrm{Ni}(1)-\mathrm{N}(3)$ & - & $95.97(8)$ & $97.18(18)$ \\
$\mathrm{O}(2)-\mathrm{Ni}(1)-\mathrm{N}(1)$ & - & $96.90(8)$ & $95.81(18)$ \\
$\mathrm{O}(2)-\mathrm{Ni}(1)-\mathrm{N}(3)$ & - & $83.60(8)$ & $83.65(18)$ \\
$\mathrm{N}(1)-\mathrm{Ni}(1)-\mathrm{N}(3)$ & - & $178.99(9)$ & $177.1(2)$ \\
\hline
\end{tabular}

been assigned to the amide- $\mathrm{CO}$ and the azomethine- $\mathrm{CN}$ stretches, respectively. In contrast, the amide-CO and the azomethine-CN stretches for $\mathbf{2}$ appear as two rather closely spaced strong bands at 1638 and $1605 \mathrm{~cm}^{-1}$, respectively. The absence of the amide- $\mathrm{NH}$ stretching band in the spectra of the two complexes $\mathbf{3}$ and $\mathbf{4}$ is consistent with the deprotonation of the amide functionalities in the corresponding ligands. Two sharp and strong bands observed at 1614 and $1552 \mathrm{~cm}^{-1}$ for 3 are most likely due to the amidate- $\mathrm{CO}^{34}$ and the amidate$\mathrm{CN}-\mathrm{NC}$-azomethine ${ }^{28,35,36}$ moieties, respectively, of the ligand $\mathrm{Fcah}^{-}$. The corresponding bands for $\mathrm{Fcbh}^{-}$in 4 have been observed at 1614 and $1585 \mathrm{~cm}^{-1}$, respectively.

Electronic absorption spectra of $\mathbf{1 - 4}$ were recorded using their dichloromethane solutions. The spectroscopic profile of $\mathbf{1}$ is very similar to that of $\mathbf{2}$. The spectroscopic profiles of $\mathbf{3}$ and $\mathbf{4}$ are also comparable to each other. The spectra of $\mathbf{1}$ and $\mathbf{3}$ are illustrated in Figure 4 and those of $\mathbf{2}$ and $\mathbf{4}$ are depicted in Figure S1 (Supplementary Information). The free Schiff bases ( 1 and 2 ) exhibit two weak absorptions at $\sim 458$ and $\sim 350 \mathrm{~nm}$ and two very strong absorptions at $\sim 296$ and $\sim 254 \mathrm{~nm}$. Ferrocene and its derivatives are well known to display similar absorption bands at comparable wavelengths. ${ }^{37-40}$ Thus, it is very apparent that all four absorption bands observed for $\mathbf{1}$ and $\mathbf{2}$ are associated with transitions involving their ferrocene fragments only. The weak absorption bands are typically assigned to the iron centred ligand field transitions, while the following two strong absorptions are attributed to ligand-to-metal and metal-to-ligand charge transfer transitions, respectively. ${ }^{37-40}$ In contrast, the nickel(II) complexes ( $\mathbf{3}$ and $\mathbf{4}$ ) display an absorption maximum at $\sim 482 \mathrm{~nm}$ of moderate intensity and four strong

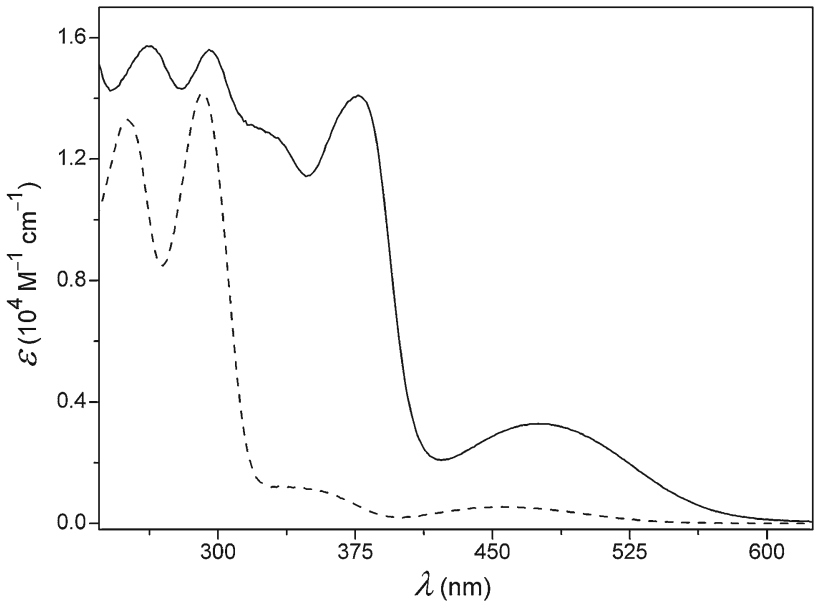

Figure 4. Electronic absorption spectra of HFcah (1) (dashed trace) and $\left[\mathrm{Ni}(\mathrm{Fcah})_{2}\right]$ (3) (solid trace) in dichloromethane.

absorptions at $\sim 384, \sim 333, \sim 300$ and $\sim 264 \mathrm{~nm}$ (Figure 4). It is very likely that the first three absorption bands are predominantly due to ligand-to-metal and ligand centred charge transfer transitions associated with the square-planar $\mathrm{NiN}_{2} \mathrm{O}_{2}$ chromophore. ${ }^{41}$ As for the free Schiff bases (1 and 2), the last two absorption bands for the complexes are also assigned to ferrocene fragment centred ligand-to-metal and metal-to-ligand charge transfer transitions, respectively.

The ${ }^{1} \mathrm{H}$ NMR spectra of $\mathbf{1 - 4}$ were obtained using $\mathrm{CDCl}_{3}$ as solvent and tetramethylsilane as internal standard. The chemical shift data given in the experimental section are according to the numbering scheme shown in Scheme 1. The spectrum of each of the two complexes clearly indicates that its two ligands are equivalent in solution. The amide-NH proton of $\mathbf{1}$ and $\mathbf{2}$ appears as a 
singlet at $\delta 9.52$ and $9.05 \mathrm{ppm}$, respectively. No such signal has been observed in the spectrum of either of $\mathbf{3}$ and 4 due to deprotonation of the amide functionalities of the coordinated ligands in them. The singlet observed at $\delta 7.68$ and $8.27 \mathrm{ppm}$ for $\mathbf{1}$ and $\mathbf{2}$, respectively, is assigned to the azomethine proton $\left(\mathrm{H}^{11}\right)$. The singlet corresponding to the azomethine proton $\left(\mathrm{H}^{11}\right)$ resonates at $\delta$ 6.83 and 7.18 ppm for 3 and $\mathbf{4}$, respectively. The upfield shift in each case is most likely the consequence of $\pi$ backdonation from metal to azomethine. ${ }^{42}$ In the cases of $\mathbf{1}$ and $\mathbf{2}$, the four protons of the substituted $\mathrm{Cp}^{-}$ring appear as two singlets, each of two-proton, at $\delta \sim 4.68$ and $\sim 4.43 \mathrm{ppm}$, while the five protons of the unsubstituted $\mathrm{Cp}^{-}$ring are observed as a singlet at $\delta \sim 4.23 \mathrm{ppm}$. The corresponding singlets are shifted downfield by $\delta \sim 0.12 \mathrm{ppm}$ for 3 and $\mathbf{4}$. The three-proton singlet due to the methyl protons of the $-\mathrm{NHC}(=\mathrm{O}) \mathrm{Me}$ fragment of $\mathbf{1}$ has been observed at $\delta 2.34 \mathrm{ppm}$, while for $\mathbf{3}$ the corresponding singlet is shifted upfield by $\delta 0.39 \mathrm{ppm}$, perhaps due to the amide deprotonation and iminolate formation. In the case of $\mathbf{2}$, a two-proton singlet observed at $\delta 7.87 \mathrm{ppm}$ is assigned to ortho protons of the phenyl ring in the $-\mathrm{NHC}(=\mathrm{O}) \mathrm{Ph}$ fragment, while the meta and the para protons are observed as a three-proton multiplet centred at $\delta 7.53 \mathrm{ppm}$. In $\mathbf{4}$, the ortho protons resonate somewhat down-field at $\delta 8.03 \mathrm{ppm}$ as a two-proton doublet, while the meta and the para protons appear slightly upfield at $\delta 7.47 \mathrm{ppm}$ as a three-proton multiplet.

\section{Redox properties}

The electron transfer characteristics of 1-4 were examined by using cyclic voltammetry. The measurements were carried out at $298 \mathrm{~K}$ with $\sim 1 \times 10^{-3} \mathrm{M}$ dichloromethane solutions of the compounds containing $0.1 \mathrm{M}$ tetrabutylammonium perchlorate as supporting electrolyte under nitrogen atmosphere using a platinum disk working electrode, a platinum wire auxiliary electrode and an $\mathrm{Ag} / \mathrm{AgCl}$ reference electrode. The ferrocenium/ferrocene $\left(\mathrm{Fc}^{+} / \mathrm{Fc}\right)$ couple was observed at $\mathrm{E}_{1 / 2}=0.35 \mathrm{~V}$ under identical conditions. All of 1-4 exhibit a quasi-reversible oxidation response with $\mathrm{E}_{1 / 2}$ value within the range of $0.23-0.50 \mathrm{~V}$. Cyclic voltammograms of $\mathbf{2}$ and $\mathbf{4}$ are shown in Figure 5 and those of $\mathbf{1}$ and $\mathbf{3}$ are given in Figure S2 (Supplementary Information). One-electron nature of this response has been inferred by comparing the peak currents with those of the ferrocene and other known one-electron redox couples under identical experimental conditions. ${ }^{35,36,43,44}$ The oxidation potential $(0.23 \mathrm{~V})$ of $\mathbf{1}$ is somewhat lower than that $(0.36 \mathrm{~V})$ of $\mathbf{2}$. On the other hand, the oxidation potential $(0.50 \mathrm{~V})$ of $\mathbf{3}$ is very close to that $(0.47 \mathrm{~V})$ of 4 . Comparison of these potentials with the potential

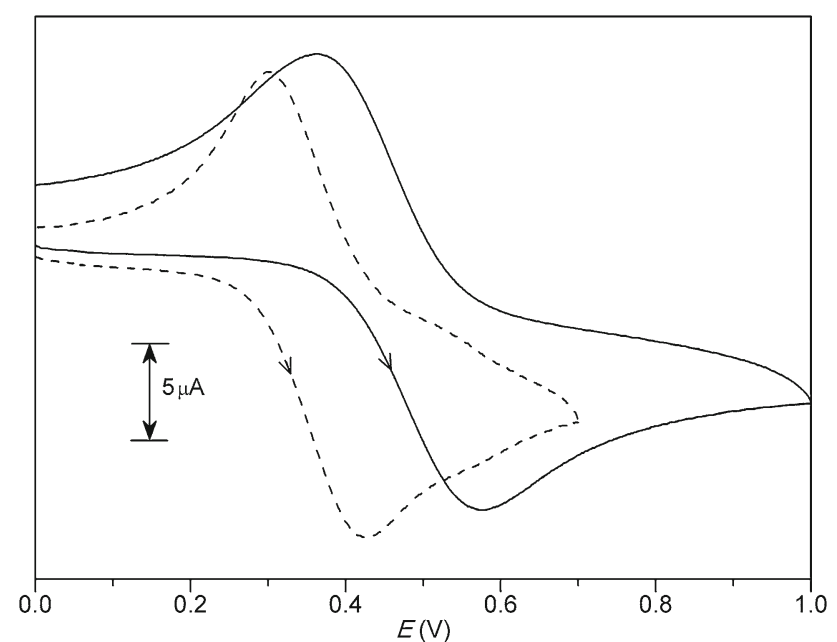

Figure 5. Cyclic voltammograms (scan rate $100 \mathrm{mV} \mathrm{s}^{-1}$ ) of HFcbh (2) (dashed trace) and $\left[\mathrm{Ni}(\mathrm{Fcbh})_{2}\right]$ (4) (solid trace) in dichloromethane using the experimental conditions described in the text.

$(0.35 \mathrm{~V})$ of the unsubstituted ferrocene redox couple clearly indicates that the oxidation response observed for not only $\mathbf{1}$ and $\mathbf{2}$ but also for $\mathbf{3}$ and $\mathbf{4}$ is iron centred. It is very likely that although the nickel centre is redox silent but its coordination makes the acylhydrazonate fragment more electron withdrawing and consequently, the iron oxidation potentials of the complexes become higher than those of the free Schiff bases.

\section{Conclusions}

Syntheses and characterization of two Schiff bases $N$-(acyl)- $N^{\prime}$-(ferrocenylidene)hydrazines (acyl = acetyl and benzoyl) and their diamagnetic nickel(II) complexes containing the angular iron(II)-nickel(II)-iron(II) array are presented. X-ray molecular structures of one of the two Schiff bases and both nickel(II) bis chelates of the deprotonated monoanionic azomethine- $\mathrm{N}$ and amidateO coordinating Schiff bases have been determined. In each of the three structures, the cyclopentadienide rings in the ferrocene fragment adopt an eclipsed conformation. The N,O-coordinating ligands form two five-membered chelate rings and a trans $-\mathrm{N}_{2} \mathrm{O}_{2}$ squareplane around nickel(II) in both complexes. Analytical and spectroscopic characteristics of all the compounds are congruent with their molecular structures. Both Schiff bases and their two complexes are redox active and display an iron centred oxidation response. We are currently engaged in synthesising and characterising $4 d$ and $5 \mathrm{~d}$ transition metal ion coordination and cyclometallated complexes with these Schiff bases and exploring the possibility of their use as effective catalysts in synthetic organic reactions. 


\section{Supplementary Information (SI)}

CCDC 1538071,1538072 and 1538073 contain the supplementary crystallographic data for $\mathbf{2} \cdot \mathrm{CDCl}_{3}, \mathbf{3}$ and $\mathbf{4} \cdot \mathrm{CHCl}_{3}$, respectively. These data can be obtained free of charge via www.ccdc.cam.ac.uk/data_request/cif, by e-mailing to data_request@ccdc.cam.ac.uk or by contacting The Cambridge Crystallographic Data Centre, 12 Union Road, Cambridge CB2 1EZ, UK; fax: (+44)1223-336-033. Supplementary Figures S1 and S2 are available at www.ias.ac.in/ chemsci.

\section{Acknowledgements}

G. N. Babu thanks the Council of Scientific and Industrial Research, New Delhi for a research fellowship (No. 09/414(1025)/2012-EMR-I). Financial assistance and instrumental facilities provided by the Department of Science and Technology, New Delhi through the FIST and the PURSE programs and by the University Grants Commission, New Delhi through the CAS and the UPE programs are gratefully acknowledged.

\section{References}

1. Kealy T J and Pauson P L 1951 A new type of organoiron compound Nature 1681039

2. Miller S A, Tebboth J A and Tremaine J F 1952 Dicyclopentadienyliron J. Chem. Soc. 632. doi:10.1039/ JR9520000632

3. Wilkinson G, Rosenblum M, Whiting M C and Woodward R B 1952 The structure of iron bis-cyclopentadienyl J. Am. Chem. Soc. 742125

4. Fischer V E O and Pfab W 1952 CyclopentadienMetallkomplexe, ein neuer Typ metallorganischer Verbindungen Z. Naturforsch., B: Chem. Sci. 7 b 377

5. Togni A and Hayashi T (Eds.) 1995 Ferrocenes: Homogeneous Catalysis, Organic Synthesis, Materials Science (Wiley-VCH: Weinheim)

6. Mamane V 2008 Metal-catalyzed cross-coupling reactions for ferrocene functionalization: Recent applications in synthesis, material science and asymmetric catalysis Mini-Rev. Org. Chem. 5303

7. Noël T and Van der Eycken J 2013 Ferrocene-derived P,N ligands: Synthesis and application in enantioselective catalysis Green Process. Synth. 2297

8. Liu Z-Q 2011 Potential Applications of ferrocene as a structural feature in antioxidants Mini-Rev. Med. Chem. 11345

9. Li P-Z and Liu Z-Q 2014 Asymmetrical mono-carbonyl ferrocenylidene curcumin and their dihydropyrazole derivatives: Which possesses the highest activity to protect DNA or scavenge radical? Med. Chem. Res. 233478

10. Fouda M F R, Abd-Elzaher M M, Abdelsamaia R A and Labib A A 2007 On the medicinal chemistry of ferrocene Appl. Organometal. Chem. 21613

11. Ornelas C 2011 Application of ferrocene and its derivatives in cancer research New J. Chem. 351973
12. Floris B 2015 Ferrocene in agriculture: From agrochemicals and soil remediation to selective chemosensors Chem. Biol. Technol. Agric. 215

13. Kadkin O N and Galyametdinov Y G 2012 Ferrocenecontaining liquid crystals Russ. Chem. Rev. 81675

14. Takahashi S and Anzai J -I 2013 Recent Progress in ferrocene-modified thin films and nanoparticles for biosensors Materials 65742

15. Xia X, Yu H, Wang L and ul-Abdin Z 2016 Recent progress in ferrocene- and azobenzenebased photoelectric responsive materials $R S C A d v .6105296$

16. Babu G N and Pal S 2016 Mono- and dinuclear palladium(II) cyclometallates with 4-R- $N^{\prime}$ (mesitylidene)benzohydrazides and mono- and diphosphines J. Organomet. Chem. 80519

17. Babu G N and Pal S 2017 Mono- and dinuclear cyclopalladates as catalysts for Suzuki-Miyaura cross-coupling reactions in predominantly aqueous media Tetrahedron Lett. 581000

18. Perrin D D, Armarego W L F and Perrin D P 1983 In Purification of Laboratory Chemicals (Pergamon: Oxford)

19. SMART Version 5.630 and SAINT-plus Version 6.45 2003 Bruker-Nonius Analytical X-ray Systems Inc., Madison, WI, USA

20. APEX2 Version 2014.9-0 and SAINT-plus Version 8.34A 2014 Bruker Analytical X-ray Systems Inc., Madison, Wisconsin, USA

21. Sheldrick G M 1997 SADABS, Program for Area Detector Absorption Correction, University of Göttingen, Göttingen, Germany

22. Sheldrick G M 2008 A short history of SHELX Acta Crystallogr. Sect. A 64112

23. Farrugia L J 1999 WinGX suite for small-molecule single-crystal crystallography J. Appl. Crystallogr. 32 837

24. Farrugia L J 1997 ORTEP-3 for windows-A version of ORTEP-III with a graphical user interface (GUI) J. Appl. Crystallogr. 30565

25. Mochida T and Yamazaki S 2002 Mono- and diferrocenyl complexes with electron-accepting moieties formed by the reaction of ferrocenylalkynes with tetracyanoethylene J. Chem. Soc. Dalton Trans. 3559. doi:10. 1039/B204168E

26. Shikhaliyev N G, Gurbanov A V, Muzalevsky V M, Nenajdenko V G and Khrustalev V N 2014 Crystal structure of 1,1-di-acetyl-ferrocene dihydrazone Acta Crystallogr. Sect. E $\mathbf{7 0} \mathrm{m} 286$

27. Das S and Pal S 2004 Cyclopalladated complexes with $\quad N$-(benzoyl)- $N^{\prime}-(2,4-$ dimethoxybenzylidene)hydrazine: Syntheses, characterization and structural studies J. Organomet. Chem. 689352

28. Mukhopadhyay A and Pal S 2009 Nickel-assisted oxidative $\mathrm{C}-\mathrm{C}$ coupling and subsequent cleavage to $\mathrm{C}=\mathrm{O}$ of active methylene group in a tetradentate ligand system: Di- and mononuclear complexes with transformed ligands Eur. J. Inorg. Chem.27 4141

29. Ghosh T, Mukhopadhyay A, Dargaiah K S C and Pal S 2010 Syntheses and structures of nickel(II) and copper(II) complexes with biacetyl bis(benzoylhydrazone): 
One-dimensional self-assembly via $\pi-\pi$ interaction and hydrogen bonding Struct. Chem. 21147

30. Song Y, Xu Z, Sun Q, Su B, Gao Q, Liu H and Zhao J 2008 Synthesis, structures, and characterization of copper(II), nickel(II), and cobalt(III) metal complexes derived from an asymmetric bidentate Schiff-base ligand J. Coord. Chem. 611212

31. Vafazadeh R, Gorji A, Ansari S and Willis A C 2012 Synthesis, characterization and crystal structure studies of nickel(II) complexes With NO donor Schiff base ligands Acta Chim. Slov. 59897

32. Basu P K, Mitra M, Ghosh A, Thander L, Lin C $-\mathrm{H}$ and Ghosh R 2014 Synthesis, crystal structure and catecholase activity of a $\mathrm{Ni}$ (II) complex derived from a tetradentate Schiff base ligand J. Chem. Sci. 1261635

33. Li X-W, Xue L-W, and Zhang C-X 2015 Synthesis, Xray structures, and antimicrobial activities of nickel(II) and copper(II) complexes with tetradentate Schiff bases Synth. React. Inorg. Met.-Org. Nano-Met. Chem. 45 512

34. Angus P M, Elliott A J, Sargeson A M and Willis A C 1999 Synthesis and properties of cobalt(III) complexes of tripodal ligands containing amide functional groups $J$. Chem. Soc. Dalton Trans. 1131. doi:10.1039/A809316D

35. Saroja J, Manivannan V, Chakraborty P and Pal S 1995 A diiron(II1) complex containing N-N bridges. Synthesis, structure, and properties Inorg. Chem. 343099

36. Sreerama S G and Pal S 2005 Dinuclear triple helicates with diazine ligands: X-ray structural, electrochemical, and magnetic studies Inorg. Chem. 446299

37. Sohn Y S, Hendrickson D N and Gray H B 1971 Electronic structure of metallocenes J. Am. Chem. Soc. 93 3603
38. Rösch N and Johnson K H 1974 An SCF X $\alpha$ scatteredwave calculation for ferrocene Chem. Phys. Lett. 24179

39. Harvey P D and Sharman J G 1990 Characterization and spectroelectrochemical properties of a binuclear trans,trans-bis(ferrocenylidene)acetone $\left[\left(\mathrm{C}_{5} \mathrm{H}_{5}\right) \mathrm{Fe}\left(\mathrm{C}_{5} \mathrm{H}_{4} \mathrm{CHCH}\right)\right]_{2} \mathrm{CO}$ Can. J. Chem. 68223

40. Colbran S B, Lee S T, Lonnon D G, Maharaj F J D, McDonagh A M, Walker $\mathrm{K}$ A and Young R D 2006 Covalently linked ferrocenyl quinones: protondependent redox behavior and charge redistribution Organometallics 252216

41. Bella S D, Fragalá I, Ledoux I, Diaz-Garcia M A and Marks T J 1997 Synthesis, characterization, optical spectroscopic, electronic structure, and second-order nonlinear optical (NLO) properties of a novel class of donor-acceptor bis(salicylaldiminato)nickel(II) schiff base NLO chromophores J. Am. Chem. Soc. 1199550

42. Keesara S, Babu G N and Pal S 2017 An acetatopalladium(II) complex with 1-benzyl- $N-(3,5-$ di-tert-butylsalicylidene)piperidin-4-amine: synthesis, structure and catalytic applications in Suzuki-Miyaura coupling of arylboronic acids with hydroxyaryl halides Appl. Organomet. Chem. doi:10.1002/aoc.3778

43. Raveendran R and Pal S 2006 Synthesis, structure and properties of di- and mononuclear ruthenium(III) complexes with $N$-(benzoyl)- $N^{\prime}$-(salicylidene)hydrazine and its derivatives Inorg. Chim. Acta 3593212

44. Rao A R B, Babu G N and Pal S 2015 A halfsandwich rhodium(III) complex with 4-bromo-N-(1pyrenylidene)aniline: Regioselective cyclorhodation of the 1-pyrenyl group J. Chem. Res. 39582 